\title{
The Impact of Market Sentiment on Fund Flow
}

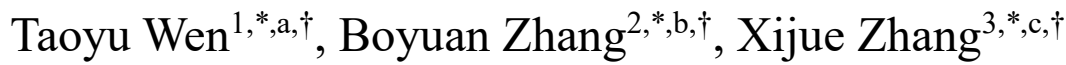 \\ ${ }^{1}$ Smeal College of Business, Pennsylvania state university, State College, 16802, United States \\ ${ }^{2}$ College of Management and Economy, Tianjin University, Tianjin, 300000, China \\ ${ }^{3}$ College of Finance and Statistics, Hunan University, Changsha, 410000, China \\ "Corresponding author.Email: ${ }^{a}$ proistop20xx@gmail.com, ${ }^{b}$ zby991223@tju.edu.cn, ${ }^{c} 1056826535 @ q q . c o m$ \\ These authors contributed equally.
}

\begin{abstract}
This paper studies the impact of market sentiment on fund flow. We collect fund data from 2010 to 2020 and relevant data to measure investor sentiment. At the same time, the fund is divided into six different types and analyzed respectively. We find that the open-ended fund, LOF fund, the open-ended fund (with a fixed closing period), and the ETF fund lead to the increase of fund redemption share with the increase of investor sentiment. Moreover, In the case of the same investor sentiment, the larger the scale of the fund, the smaller the redemption share of the fund. Second, FOFs and innovative closed-end funds are buying more shares as investor sentiment grows. At the same time, in the same investor sentiment, the larger fund size will reduce the subscribing share. This study provides a new perspective for understanding the relationship between fund performance and fund flow in China and is conducive to investors making rational investment decisions.
\end{abstract}

Keywords: investor sentiment, fund performance, fund flow, turnover rate, PCA proxy.

\section{INTRODUCTION}

Investor sentiment refers to the systematic deviation of investors' future expectations, which is called investor sentiment [1]. Investor sentiment is a difficult concept to measure. It reflects the investment wishes or expectations of market participants. So why should we consider investor sentiment, and what are the advantages of investor sentiment? The simplest and most obvious reason is that emotions govern the investment behaviour of all investors, and this emotion control may be difficult to detect. From an academic point of view, they can be called rational investors and irrational investors. Rational investors usually make investment decisions based on fundamental information and will conduct arbitrage when they find that the stock price deviates from its intrinsic value. Irrational investors make "wrong" investment decisions based on personal judgment, such as overconfidence or pessimism. They will consider not only fundamental information but also other more alternative information. Of course, The information that may be irrational by investors is incomplete, leading to incorrect information in their feedback. However, it should be noted that this does not mean that rational investors are technologically mature investment bosses or institutional investors, and irrationality does not mean our ordinary investors. Studies have proved that professional, institutional investors are more susceptible to "emotions" and make irrational trading behaviours [2]. However, what everyone can hardly deny is that investor sentiment is a very important concept. In economic activities, sentiment is an uncertain factor, which affects investors' subjective judgments on future returns, and then affects their investment behaviour. After joining forces, it will have a great impact on the market. The logic of the influence of investor sentiment on future market volatility lies in the gradual amplification of positive and negative news. There is no uniform standard for the definition of investor sentiment.

The main issue we discussed in this paper is how the market sentiment would impact fund flow. Generally, investors use fund flows to judge the investor sentiment of a particular industry or market. If net inflows for bond funds are substantially positive in a given month, it is a sign of investor optimism about the fixed-income market. If the fund flow changes. It may be related to the latest news in the company, the general trend in the industry, or new projects and products. A positive change in capital flows indicates an increase in inflows and a decrease in outflows. In contrast, negative capital 
flows mean fewer inflows and more outflows. For example, when I was an investor, I invested $\$ 10,000$ in the stock market or the fund market. I am hesitating now. Then, I discovered that investor sentiment in the stock market is high. So I chose to invest more in the stock market. So, this caused the outflow of the fund market

\subsection{Paper organization}

The rest of the paper is organized as follows: Section 2 represents the literature review. Section 3 represents the Data. Section 4 represents empirical results. Section 5 represents the Conclusion.

\section{LITERATURE REVIEW}

The impact of investor sentiment on the financial market is shown in terms of stock prices. When investors are enthusiastic, they will choose to increase their shares. Investors ' rising demand at this time is represented as a rising stock price, and even when the stock prices are overvalued, they will continue to buy and partially ignore the price bubble. When investor sentiment, the impact will quickly produce the same effect, lasting for some time, slowly return to the stable. The stock market is impacted, the reaction is not as fast as investor sentiment, indicating that investor sentiment is fluctuating before the stock market, the mood has a certain prediction effect on the stock market.

At the same time, there is also a spatial interaction on the impact of emotions on share prices. Investor sentiment is the characteristic determinant of asset price fluctuations, which affects the price fluctuations of the asset and affects the price fluctuations of other similar assets. And the spatial interaction of investor sentiment on the cross-section of the stock price is more sensitive to economic distance than to geographical distance [3]. In terms of the speed of the impact, once the investor sentiment fluctuates, the impact on the stock price of the same type of listed companies will be faster than on the companies close to space.

Investor sentiment will also have an impact on the liquidity of the stock market. When the stock market fluctuates greatly, both rise or fall will positively or negatively impact investors, attract more investors to buy or sell in large numbers, the stock market turnover rate significantly increases, and the liquidity increases [4]. But at the same time, it may also lead to the expansion of the sales price difference, increasing the cost and difficulty of the transaction, liquidity has weakened. New investors are the new blood of the stock market. When investors are high, both rational and irrational investors may enter the market on a large scale, creating better preconditions for the change of the stock market. For newly opened investors, as an additional, the amount of funds is conducive to enriching the stock market's liquidity. While they have a process of gradually familiar with the stock market, phased increase and decrease of positions, so the impact on the popularity of the stock market will continue for a long time.

Compared with the large market stocks, small and medium-sized stocks are more sensitive to emotional changes; compared with larger companies, small company stock trading volume, poor liquidity, such stocks have greater investment risk. The stock has less market information, and investors are prone to shadow capture and respond quickly to noise information. Because small-cap stocks are more vulnerable to sentiment when investor sentiment rises, small-cap stocks and large-cap share yields rise simultaneously. Still, the increase of small-cap stocks is more, so the income difference between small-cap stocks and large-cap stocks is increased. On the contrary, when the stock yield of different sizes decreased, but the decline of small-cap stocks was relatively large, reducing the income difference between small-cap stocks [5].

The definition of fund flow is the net of all cash inflows and outflows in and out of various financial assets. Fund flow is usually measured on a monthly or quarterly basis. The performance of an asset or fund is not taken into account, only share redemptions, or outflows, and share purchases, or inflows. Net inflows create excess cash for managers to invest, which theoretically creates demand for securities such as stocks and bonds.[6] Generally, investors use fund flows to judge the investor sentiment of a particular industry or market. For example, if net inflows for bond funds are substantially positive in a given month, investor optimism about the fixed-income market is a sign of investor optimism. If the fund flow changes. It may be related to the latest news in the company, the general trend in the industry, or new projects and products. A positive change in capital flows indicates an increase in inflows and a decrease in outflows. In contrast, negative capital flows mean fewer inflows and more outflows. While occasional shifts may not indicate issues within the company, prolonged negative fund flows can be a sign there are some issues present, as this is a reflection of income not being sufficient to meet the company's expenses. If this trend continues, it could mean the company needs to acquire a form of debt to continue operations.[6]

\section{DATA SOURCE}

The sample period is from 2010-01-01 to 2020-12-31, selected P / E ratio, value-weighted market turnover rate, value-weighted average market yield, and all A-share enterprises as the original sample. The data are obtained from the RESSET database, and the observations were excluded according to the following conditions: (1) Funds in an abnormal state. (2) 
Companies listed after 2011 were excluded because the sample period required 10 years. and (3) Remodel data missing or abnormal from related variables.

\subsection{Investor sentiment variable construction}

Table 1. Total variance of the interpretation

\begin{tabular}{|c|c|c|c|c|c|c|}
\hline \multirow[t]{2}{*}{ Element } & \multicolumn{3}{|c|}{ Initial Eigenvalue } & \multicolumn{3}{|c|}{$\begin{array}{l}\text { Extract the Sum of } \\
\text { Squares and Load It }\end{array}$} \\
\hline & Total & VAR \% & $\begin{array}{l}\text { Accumu } \\
\text { lation } \%\end{array}$ & Total & VAR \% & $\begin{array}{l}\text { Accumu } \\
\text { lation \% }\end{array}$ \\
\hline 1 & 1.856 & 61.871 & 61.871 & 1.856 & 61.871 & 61.871 \\
\hline 2 & .760 & 25.325 & 87.196 & & & \\
\hline 3 & .384 & 12.804 & 100.00 & & & \\
\hline
\end{tabular}

Investor sentiment is an expectation of investment risk and expected return, making investors form a subjective judgment of the market changes, thus forming an emotional reflection of investors to the market, which is reflected by the change in investors' future investment behaviour. Investor sentiment is a very abstract concept, but everyone can clearly feel its existence and be affected by it in the market. Therefore, when studying investor behaviour and financial markets, investor sentiment is a very important concept, need to use other indicators to quantify it and accurately measure indicators. In this paper, we use the indirect index method. That is part of market indicators that can affect investor sentiment will be used to make it can measure mood variables more accurately. When reading the literature, in The Impact of Investor Sentiment on the Scale Effects, Environmental Uncertainty, Investor Sentiment, and Enterprise Investment Efficiency and other literature, the author used indicators such as turnover rate, price/earnings ratio, stock yield, the average yield on the first day of IPO listing, number of new shares and other indicators as tools to measure investor sentiment. After considering the difficulty of data acquisition and the extent of the impact on investor sentiment, we chose the circulation market value-weighted monthly turnover rate and circulation market value-weighted average market monthly return, the market $\mathrm{P} / \mathrm{E}$ ratio as a measure of investor sentiment measurement tools. We selected the monthly data from January 1, 2010, to December 31, 2020, first standardized the three indicators and obtained the standardized data, then complete the main component analysis, taking the final comprehensive index as the final measure of investor sentiment. The explanatory power of the comprehensive indicators of the three standardized indicators is shown in the table. The circulation market value-weighted monthly turnover rate is $61.871 \%$, the circulation market value-weighted average market monthly return is $25.325 \%$, and the market $\mathrm{P} / \mathrm{E}$ ratio is $12.804 \%$.

\section{EMPIRICAL DATA SOURCE}

The data in this paper are from RESSET Database, and all fund data are collected from the start date of January 1, 2010, to October 1, 2020. The second part is to screen the fund data, including a single statistical period of three months (one quarter). The start dates of funds are January 1, April 1, July 1, and October 1 of each year. Deadlines are March 31, June 30, September 30, and December 31 of each year. Prevent subsequent changes in the fund share at individual times from affecting the accuracy of the results. Through the above screening conditions, a total of 151,631 effective samples were screened.

Then, according to different fund types, all the data sets are divided into data sets of 6 different fund types. Among them, the number of Open-ended funds is 112,776; The sample number of LOF funds is 7281 . The sample number of FOF funds is 5144; The number of innovative closed-end fund samples is 7201; The number of Open-ended samples (with a fixed closed period) is 15245; The sample number of ETF linked funds is 3974, and the total sample is 151631. (The remaining 10 observations are contractual closed-end funds, which cannot be analysed due to the lack of detailed subscription and redemption data.)

\section{EMPIRICAL RESULTS AND ANALYSIS}

\subsection{The impact of investor sentiments on fund flow}

The influence of investor sentiments on fund cash flow is shown in Table 1, where the value in brackets is the $\mathrm{T}$ value of the variable.

We can see that in the Open-ended, LOF, Open-ended (with a fixed closed period), and ETF funds, the turnover rate, and PCA coefficients are all negative. This suggests that the higher investor sentiment, the greater redemptions. Among them, the variable coefficient of the turnover rate of the open-end fund is the smallest, and the turnover rate is -1151.997 . The PCA coefficient of the open-ended fund (with the fixed closing period) is the smallest, and the PCA is -28594.754. The main reason may be that open-ended funds are easier to purchase and redeem than other fund types. At the same time, the fund volume is large, and small and medium investors generally dominate it, so it is extremely vulnerable to the impact of investor sentiment fluctuations. 
On the other hand, the investor sentiment coefficients of FOF and innovative closed-end funds are both positive. The turnover rate and PCA coefficient of FOF were 0.532 and 4.92, respectively. The turnover rate and PCA of an innovative closed-end fund are 1.934 and 57.183, respectively. This means that the stronger investor sentiment, the greater number of subscriptions for these types of funds.
The main reason may be that FOF has less risk and less influence on investors compared with other fund types. On the other hand, compared with the open-ended fund, the closed-end fund is more difficult to redeem, and it is difficult to produce huge fluctuations in a short time.

Table 2. The impact of investor sentiments on fund flow

\begin{tabular}{|c|c|c|c|c|c|c|c|}
\hline Type & $\begin{array}{l}\text { Turnover } \\
\text { rate }\end{array}$ & & PCA proxy & Fund size & & $\mathrm{R}^{2}$ & Observation \\
\hline \multirow[t]{2}{*}{ Open-ended } & -1151.997 & $(-0.341)$ & & 7133126 & (12.068) & 0.001 & 112776 \\
\hline & & & -17059.132 & 7063109 & (12.73) & 0.001 & \\
\hline \multirow[t]{2}{*}{ LOF } & -0.284 & $(-0.596)$ & & 1138.07 & $(7.752)$ & 0.008 & 7281 \\
\hline & & & -12.186 & 1123.287 & (7.901) & 0.008 & \\
\hline \multirow[t]{2}{*}{ FOF } & 0.523 & (3.991) & & 128.321 & $(4.112)$ & 0.009 & 5144 \\
\hline & & & 4.92 & 165.572 & $(5.574)$ & 0.006 & \\
\hline \multirow{2}{*}{$\begin{array}{l}\text { Innovative } \\
\text { Close-end }\end{array}$} & 1.934 & (16.179) & & 141.05 & (4.793) & 0.043 & 7201 \\
\hline & & & 57.183 & 248.18 & (8.509) & 0.035 & \\
\hline \multirow{2}{*}{$\begin{array}{l}\text { Open-ended } \\
\text { (with a fixed } \\
\text { closed period) }\end{array}$} & -774.507 & $(-0.854)$ & & 1189253 & $(6.727)$ & 0.003 & 15245 \\
\hline & & & -28594.754 & 1140004 & $(6.808)$ & 0.003 & \\
\hline \multirow[t]{2}{*}{ ETF } & -47.452 & $(-1.446)$ & & 92605.56 & (12.19) & 0.038 & 3974 \\
\hline & & & -1921.286 & 89957.25 & (12.349) & 0.038 & \\
\hline
\end{tabular}

\subsection{The effect of the cross between investor sentiment and ending share (logarithmic value) on fund flow}

The effect of the cross between investor sentiment and ending share (logarithmic value) on fund flow is shown in Table 2. It can be seen that the investor sentiment coefficients of open-ended funds, LOF, open-end funds (with a fixed closed period), and ETF are still negative after adding the cross item. Among them, the minimum value of the turnover rate coefficient is -95091.765 , while the minimum value of the PCA coefficient is -2023755.356 .
However, all the crosses are positive, which means that the larger the fund is under the premise of the same investor sentiment, the smaller the redemption share will be.

On the other hand, the investor sentiment coefficient of FOF and the innovative closed-end fund is still positive, and the maximum value of turnover rate coefficient and PCA coefficient are both innovative closed-end fund coefficients (14.815 and 370.157).

And their crosses are the opposite, all negative. This means that the larger the fund is under the same sentiment, the smaller the subscription will be. 
Table 3. The effect of the cross between investor sentiment and ending share (logarithmic value) on fund flow

\begin{tabular}{|c|c|c|c|c|c|c|c|c|c|c|c|c|}
\hline Type & $\begin{array}{l}\text { Turnover } \\
\text { rate }\end{array}$ & & $\begin{array}{l}\text { Cross of } \\
\text { turnover } \\
\text { rate }\end{array}$ & & PCA proxy & & $\begin{array}{l}\text { Cross of } \\
\text { PCA }\end{array}$ & & Fund size & & $\mathrm{R}^{2}$ & Observation \\
\hline \multirow[t]{2}{*}{ Open-ended } & -95091.765 & $(-3.448)$ & 11160.155 & (3.472) & & & & & 12987431.31 & $(7.269)$ & 0.002 & 112776 \\
\hline & & & & & -1875744.453 & $(-2.204)$ & 221670.772 & (2.203) & 7120397.133 & (12.819) & 0.001 & \\
\hline \multirow[t]{2}{*}{ LOF } & -8.342 & $(-1.489)$ & 0.94 & (1.453) & & & & & 1648.923 & (4.327) & 0.009 & 7281 \\
\hline & & & & & -343.873 & $(-1.873)$ & 38.538 & (1.814) & 1121.162 & (7.887) & 0.009 & \\
\hline \multirow[t]{2}{*}{ FOF } & 7.815 & (6.905) & -0.903 & $(-6.486)$ & & & & & -353.567 & $(-4.391)$ & 0.017 & 5144 \\
\hline & & & & & 103.364 & $(2.658)$ & ${ }^{1} 12.166$ & $(-2.549)$ & 158.013 & (5.296) & 0.007 & \\
\hline \multirow[t]{2}{*}{$\begin{array}{l}\text { Innovative } \\
\text { Close-end }\end{array}$} & 14.815 & (15.374) & -1.607 & $(-13.468)$ & & & & & -734.427 & $(-10.315)$ & 0.067 & 7201 \\
\hline & & & & & 370.157 & (11.218) & _39.59 & $(-9.556)$ & 205.014 & (6.990) & 0.047 & \\
\hline \multirow[t]{2}{*}{$\begin{array}{l}\text { Open-ended } \\
\text { (with a fixed } \\
\text { closed period) }\end{array}$} & -62255.001 & $(-7.216)$ & 7334.124 & (7.166) & & & & & 505880.39 & (8.904) & 0.007 & 15245 \\
\hline & & & & & -2023755.356 & $(-7.452)$ & 237641.693 & (7.394) & 1145179.101 & (6.851) & 0.007 & \\
\hline \multirow[t]{2}{*}{ ETF } & -3473.694 & $(-10.793)$ & 419.216 & (10.699) & & & & & 306259.367 & (14.361) & 0.065 & 3974 \\
\hline & & & & & -112697.88 & $(-10.915)$ & 13540.513 & (10.787) & 87261.448 & (12.150) & 0.065 & \\
\hline
\end{tabular}

\section{CONCLUSION AND SUGGESTIONS}

Much empirical evidence shows that investor sentiment has a substantial impact on the financial markets. In this paper, we construct new investor sentiment variables to study their impact on the fund market. Empirical results show that in the fund market, a lot of redemption occurs when investors are depressed. When investor sentiment is high, a lot of subscription behaviour occurs.

For investors, when their own emotions are affected by the market fluctuations, we should first judge the cause of the fluctuations to make a rational judgment, rather than allowing the emotions to develop and cause stronger market fluctuations.

For fund managers, when the mood of many investors fluctuates, the first thing to do is predict future market trends through changes in investor sentiment. Predict future market trends, make price forecasts, and make corresponding decisions to make a profit or reduce losses.
For enterprises, when market fluctuations affect investors' emotions, they should first determine the cause of the market fluctuations and make corresponding policy adjustments according to the reasons to calm down investors, make a rational judgment, and maintain the market's stability.

\section{REFERENCES}

[1] Stein, Jeremy C. "Chapter 17. Rational Capital Budgeting in an Irrational World". Advances in Behavioral Finance, Volume II, edited by Richard H. Thaler, Princeton: Princeton University Press, 2005 , pp. 605-632. https://doi.org/10.1515/9781400829125-020

[2].Brown, G. W., \& Cliff, M. T. (2004). Investor sentiment and the near-term stock market. Journal of empirical finance,11(1), 1-27.

[3] Shangwei Jiang,and Xiu Jin."The impact of investor sentiment on the stock price from the perspective of spatial interaction." Journal of Northeastern University (The Natural Science Edition) 
41.01(2020):143-147.

doi:CNKI:SUN:DBDX.0.2020-01-025.

[4] Yong Meng,and Jing Chang."The impact of investor sentiment on the scale effects." Statistics and Information Forum 34.04(2019):98-104. doi:CNKI:SUN:TJLT.0.2019-04-014.

[5] Yuansong Tong."Research on the relationship between investor sentiment and stock market liquidity and volatility." Technical economy and management research .02(2021):76-82. doi:CNKI:SUN:JXJG.0.2021-02-015.

[6] Chen, J. (2021, May 19). Fund Flow. Investopedia. https://www.investopedia.com/terms/f/fund-flow.as p.Factors that affect Fund Flow

[7] Binyuan Luo, and Chunhong Yang. "Environmental uncertainty, investor sentiment, and corporate investment efficiency. "Monthly Accounting Journal.24 (2020): 32-40. doi:10.19641/j.cnki.42-1290/f.2020.24. 005

[8] Ailian Zhang, and Chenggang Guo. "The asymmetric impact of investor sentiment on the heterogeneous stock markets. "Statistics \& Information Forum 35.04 (2020): 113-118. doi:CNKI:SUN:TJLT.0.2020-04-014.

[9] Ruijun Zhang. "Investor sentiment, manager overconfidence, and corporate investment level. "Chinese CPA.05 (2021): 39-44. doi:10.16292/j.cnki.issn1009-6345.2021.05.004.

[10] Qinye Lu, and Hao Chen. "Media reports, investor sentiment, and stock price volatility. "Financial Issues Research.03 (2021): 60-67. doi:10.19654/j.cnki.cjwtyj. 2021.03.007. 